\title{
Plasma chromogranin $A$ in incidental non-functioning, benign, solid adrenocortical tumors
}

Giampaolo Bernini, Angelica Moretti, Vincenzo Fontana ${ }^{4}$, Cinzia Orlandini ${ }^{1}$, Paolo Miccoli ${ }^{2}$, Piero Berti ${ }^{2}$, Fulvio Basolo ${ }^{3}$, Pinuccia Faviana ${ }^{3}$, Michele Bardini and Antonio Salvetti

Departments of Internal Medicine, ${ }^{1}$ Oncology, ${ }^{2}$ Surgery and ${ }^{3}$ Oncology, Transplants and Advanced Technologies in Medicine, University of Pisa, Pisa, Italy and ${ }^{4}$ Department of Environmental Epidemiology and Biostatistics, National Cancer Research Institute of Genoa, Genoa, Italy

(Correspondence should be addressed to G Bernini, Department of Internal Medicine, University of Pisa, Via Roma 67, 56100 Pisa, Italy;

Email: g.bernini@med.unipi.it)

\begin{abstract}
Objective: To evaluate whether adenomas arising from the adrenal cortex, a tissue of epithelial origin, are associated with high chromogranin A ( $\mathrm{CgA}$ ) levels and whether such tumors may express and release this protein. In addition, to investigate whether high CgA levels imply a neuroendocrine differentiation of the adrenocortical adenomas and, therefore, represent a humoral marker of malignant transformation of these tumors.

Design: Plasma $\mathrm{CgA}$ of 80 patients with non-functioning, benign adrenocortical adenomas was compared with that of 137 tumor-free subjects. In 15 patients, the masses were surgically removed and CgA was measured 2 months later. The other 65 patients with adrenocortical adenomas underwent clinical and radiological follow-up (range 24-36 months).

Methods: CgA was evaluated by immunoradiometric assay in peripheral blood and by immunohistochemistry in adrenal tissue specimens.

Results: An increase in plasma $\mathrm{CgA}(P<0.001)$ was observed in patients with adrenocortical adenomas $(83.4 \pm 7.5 \mathrm{ng} / \mathrm{ml})$ in comparison with tumor-free subjects $(43.1 \pm 1.5 \mathrm{ng} / \mathrm{ml})$. The prevalence of high $\mathrm{CgA}$ levels was $25 \%$ in the former and $0.7 \%$ in the latter. By multiple regression analysis, an increase $(49 \%)$ in the expected median $\mathrm{CgA}$ value was estimated for adrenocortical adenomas $(P<0.001)$. Receiver operating characteristic analysis showed a good diagnostic performance of $\mathrm{CgA}$ in identifying patients with adrenocortical adenomas (pure accuracy $=0.78,95 \%$ $\mathrm{CI}=0.71-0.84)$. In the operated patients, $\mathrm{CgA}$ levels did not change before $(80.6 \pm 16.5 \mathrm{ng} / \mathrm{ml})$ and after $(74.3 \pm 16.3 \mathrm{ng} / \mathrm{ml})$ surgery and in no case was $\mathrm{CgA}$ immunoreactivity found in adenoma tissues. The non-operated patients did not develop signs or symptoms of disease and showed no features of malignant transformation of the masses.

Conclusions: Our data showed a strong association between adrenocortical adenomas and high $\mathrm{CgA}$ levels. $\mathrm{CgA}$ hypersecretion was not due to adenoma tissue, which did not show immunoreactivity for $\mathrm{CgA}$. Finally, elevated $\mathrm{CgA}$ levels did not represent a humoral marker of malignant transformation of cortical adenomas.
\end{abstract}

European Journal of Endocrinology $151215-222$

\section{Introduction}

In several endocrine and neuroendocrine cells, chromogranin A (CgA), a $48 \mathrm{kDa}$ acid glycoprotein, is co-stored in secreting granules and co-released with resident hormones $(1-3)$. For this reason, $\mathrm{CgA}$ is currently used as a tissue marker for many tumors with endocrine activity (4-7). However, growing evidence suggests that blood $\mathrm{CgA}$ measurement is likewise very useful for identifying and following-up patients with neuroendocrine tumors $(8-14)$.

Recently, elevated levels of $\mathrm{CgA}$ have been reported in patients with cancers of epithelial origin, such as prostate, breast, ovary, pancreas and liver cancer (15-19).
The ability to synthesize $\mathrm{CgA}$ implies a neuroendocrine differentiation of these epithelial tumors. Such an event is a key step in tumor biology, since it is frequently associated with a poor prognosis $(8,15,20,21)$. The presence of serum markers of this transformation might therefore identify more aggressive tumors.

The adrenal cortex is of epithelial origin and cortical adenomas are benign lesions and the risk of malignant transformation, albeit low, is present (22). Our previous study (12), while confirming the utility of plasma CgA measurement in the diagnosis of pheochromocytomas and gastroenteropancreatic tumors, unexpectedly showed elevated CgA levels in six of 25 patients with benign adrenal cortex tumors. 
In order to verify this finding in a larger cohort of patients, we compared plasma $\mathrm{CgA}$ levels in 80 patients with non-functioning, benign, adrenocortical tumors with levels found in 137 tumor-free subjects. Furthermore, to investigate whether $\mathrm{CgA}$ may be synthesized and released by adrenocortical adenomas, plasma $\mathrm{CgA}$ was measured before and after surgery in 15 patients. $\mathrm{CgA}$ immunoreactivity in the removed adenoma tissues was then evaluated by immunohistochemistry.

\section{Materials and methods}

\section{Subjects}

In this observational study patients were selected from among those referred to our unit (Department of Internal Medicine) from 1999 to 2000 for the presence of adrenal masses.

The following inclusion criteria were adopted: (a) incidental discovery of the adrenal mass by radiological investigation performed for unrelated reasons; (b) absence of symptoms and signs of endocrine and neuroendocrine disease, except for hypertension, disturbed glucose tolerance and obesity; (c) no abnormalities in glucocorticoid (urine cortisol, plasma adrenocorticotropin and cortisol before and after 1 and $2 \mathrm{mg}$ dexamethaxone suppression tests), mineralocorticoid (upright plasma renin activity and plasma and urine aldosterone), androgen (plasma free and total testosterone, androstenedione, dehydroepiandrosterone sulphate and 17-hydoxyprogesterone) or catecholamine (plasma and urine) and methanephrine levels; (d) radiological and/or scintigraphic features of non-malignancy. On computed tomography (CT), inclusion criteria required adrenal masses to be solid, small (usually $<3.5 \mathrm{~cm}$ ), rounded, well-marginated, homogeneous, with lower than water density $(<0-15$ Hounsfield Units) and absent or mild homogeneous CT enhancement after i.v. contrast, without hemorrhage, necrosis or calcification. ${ }^{131} \mathrm{I}-6 \beta$-norcholesterol scintigraphy had to show concordant or symmetrical uptake of the radiotracer; (e) no mass size increase and no development of specific signs and symptoms of disease on adequate follow-up (range 8-14 months).
On the basis of these inclusion criteria, we excluded patients with adrenal pheochromocytoma and selected only 80 patients ( 62 hypertensive and 18 normotensive) with incidental, asymptomatic, non-functioning, solid and benign tumors of the adrenal cortex (45 right sided, 12 left sided and 23 bilateral with maximum diameter of the mass of $26.3 \pm 1.26 \mathrm{~mm}$, means \pm S.E.).

One hundred and thirty-seven tumor-free subjects (83 essential hypertensive and 54 normotensive subjects) were also investigated after careful exclusion of the presence of adrenal masses on CT, magnetic resonance or ultrasonography.

Overall, 80 patients with adrenocortical tumors and 137 tumor-free subjects were investigated. In both groups, normotensive and hypertensive subjects were analysed together as in our previous reports $(12,23)$ we showed that, at least with this method, CgA levels in normotensive and essential hypertensive subjects are superimposable. Patients with serum creatinine $>1.5 \mathrm{mg} / \mathrm{dl}$ were not enrolled to avoid the wellknown false-positive $\mathrm{CgA}$ levels for hormone-secreting tumors in subjects with renal failure $(8,24)$. Patients taking omeprazol were also excluded since this drug increases CgA levels (25). Demographic and clinical data for our subjects are given in Table 1.

\section{Experimental design}

All subjects were maintained on their usual diet without salt restriction, except for essential hypertensive subjects who observed a salt-controlled diet $(80-100 \mathrm{mmol} /$ day sodium and $60-80 \mathrm{mmol} / \mathrm{day}$ potassium). Patients taking drugs (anti-hypertensives or other drugs) suspended medication for at least 2 weeks prior to the study. On the test day, all subjects collected 24-h urine samples for creatinine determination and underwent blood sampling (between 0800 and $0900 \mathrm{~h}$ ) after overnight fasting and in the sitting position. An indwelling 21 gauge scalp vein needle was inserted in an antecubital vein and was then used, after 15-20 min, for creatinine, catecholamine and CgA measurements. Blood pressure was recorded by mercury sphygmomanometer in accordance with recent guidelines (26).

Table 1 Demographic and clinical data of tumor-free subjects and of patients with adrenocortical tumors. Values are means \pm S.E. with range in parentheses.

\begin{tabular}{lccr}
\hline Variables & Tumor-free subjects $(n=137)$ & Adrenocortical tumors $(n=80)$ & $\boldsymbol{P}$ value \\
\hline Gender (male/female) & $98 / 39$ & $38 / 42$ & $<0.001^{a}$ \\
Age (years) & $41.8 \pm 1.1(17-75)$ & $57.3 \pm 1.1(23-79)$ & $<0.001$ \\
Systolic blood pressure $(\mathrm{mmHg})$ & $138.9 \pm 1.6$ & $147.0 \pm 2.3$ & 0.003 \\
Diastolic blood pressure $(\mathrm{mmHg})$ & $89.7 \pm 1.0$ & $90.0 \pm 1.2$ & 0.836 \\
Plasma creatinine $(\mathrm{mg} / \mathrm{dl})$ & $0.90 \pm 0.01$ & $0.97 \pm 0.03$ & 0.024 \\
Noradrenaline $(\mathrm{pg} / \mathrm{ml})$ & $248.6 \pm 9.5$ & $335.1 \pm 17.9$ & $<0.001$ \\
Adrenaline $(\mathrm{pg} / \mathrm{ml})$ & $31.2 \pm 1.7$ & $36.4 \pm 2.1$ & 0.058 \\
\hline
\end{tabular}

$P$, by unpaired Student's $t$-test; ${ }^{a}$ One degree of freedom chi-squared test. 
Fifteen patients with adrenocortical adenomas underwent surgery by voluntary choice $(n=12)$ and for tumor size over $35 \mathrm{~mm}(n=3)$. In the operated patients, the above-described protocol was repeated 2 months or more after operation. The other 65 patients underwent clinical and radiological follow-up (range 24-36 months) in order to detect signs or symptoms of possible malignant transformation of the mass.

Patients and controls gave their informed consent to the study which was approved by the local ethical committee.

\section{Assays}

Serum creatinine was measured by a standard technique. Plasma catecholamines and $\mathrm{CgA}$ were measured using the same blood samples collected into chilled anti-coagulant (EGTA plus L-glutathione reduced for catecholamines; heparin and trasylol for $\mathrm{CgA}$ ) glass tubes. Blood was spun down in a refrigerated centrifuge and the plasma was stored at $-80^{\circ} \mathrm{C}$ until the assay. Catecholamines and $\mathrm{CgA}$ were then assayed in duplicate and in the same run.

Catecholamines were analyzed by high-performance liquid chromatography, as previously described (27). Within-run precision was $10 \%$, while the reproducibility of peak height was $1.2 \%$ and day-to-day precision of quantitative results was $0.7 \%$. Intra- and interassay coefficients of variation (C.V.) for noradrenaline were 14\% and $20 \%$ respectively. Intra- and interassay C.V. values for adrenaline were $17 \%$ and $22 \%$ respectively. The reference range for noradrenaline was $<600 \mathrm{pg} / \mathrm{ml}$, and for adrenaline $<80 \mathrm{pg} / \mathrm{ml}$ in a sitting position.

CgA was measured by a solid-phase two-site immunoradiometric based on monoclonal antibodies that bind to two distinct contiguous epitopes within the 145-245 region of CgA (CgA-RIA CT; Cis Bio International, Gif-Sur Yvette Cedex, France) (28). The first antibody was coated onto the solid phase and the second, used as a tracer, was radiolabeled with ${ }^{125} \mathrm{I}$. CgA (molecules or fragments) present in the standards (recombinant human $\mathrm{CgA}$ ) was sandwiched between the two antibodies. Thus, by using antibodies directed against the median part of the protein, only the region of $\mathrm{CgA}$ unexposed to proteolytic processes was involved, allowing detection of the intact form and major fragments of the molecule. Intra- and interassay C.V. values were $2.5 \%$ and $7.0 \%$ respectively, while assay sensitivity was $1.5 \mathrm{ng} / \mathrm{ml}$. Values obtained for anti-coagulated plasma in 162 normal subjects were: median $41.6 \mathrm{ng} / \mathrm{ml}$; range $19-98.6 \mathrm{ng} / \mathrm{ml}$.

\section{Specimens}

Specimens $(n=15)$ of adrenal tissue were formalinfixed, paraffin-embedded and stained with hematoxylin-eosin for histological processing.

\section{Immunohistochemistry}

Tissue sections ( $4 \mu \mathrm{m}$ thick) were dewaxed and endogenous peroxidase activity was blocked with $0.3 \%$ hydrogen peroxide in methanol for $15 \mathrm{~min}$. After rinsing in distilled water, the sections were then immersed in $0.03 \mathrm{mM}$ citrate buffer ( $\mathrm{pH}$ 6.0) and incubated at 300 watts for $30 \mathrm{~min}$ in microwaves.

Monoclonal anti-chromogranin antibody, clone LK2H10, were purchased from Ventana Medical Systems (Novocastra Laboratories Ltd, Newcastle, UK). Ventana medical systems' anti-chromogranin primary antibody is an antibody which binds to chromogranin in paraffin-embedded tissue sections. The specific antibody was localized by biotin-conjugated secondary antibody formulation that recognized rabbit and mouse immunoglobulins. This step was followed by addition of an avidin-streptavidin-enzyme conjugate that binds to the biotin present on the secondary antibody. The specific antibody-secondary antibody-avidin/streptavidin-enzyme complex was then visualized using a precipitating enzyme reaction product which is readily detected by light microscopy. Each step was incubated for a precise time and temperature. At the end of each incubation step, a Ventana automated slide stainer washed the sections to stop the reaction and remove unbound material that would hinder the desired reaction in subsequent steps. It also applies liquid coverslip, which minimizes evaporation of the aqueous reagents from the specimen-containing slide. The peroxidase reaction was visualized by incubating the sections with 3,3'-diaminobenzidine; the sections were counterstained with hematoxylin.

Positive controls consisted of medullary thyroid carcinoma known to express $\mathrm{CgA}$ antigen. Negative controls were obtained by omitting primary antibodies.

The positivity index was obtained by counting almost 500 cells for lesions in pathological tissue on ten $\times 250$ fields and calculating the percentage of cells with cytoplasmatic CgA immunoreactivity. Specimens were considered positive when at least $10 \%$ of cells showed distinct cytoplasmatic staining.

\section{Statistical analysis}

To evaluate the relationship between $\mathrm{CgA}$ and the presence/absence of adrenal mass (disease status), univariate and multivariate statistical methods were used. Paired and unpaired $t$-tests were used to assess interand intra-group differences. Descriptive analyses were also carried out by creating and examining the conditional distribution of $\mathrm{CgA}$ by covariates (tumor diameter, age at examination, gender, hypertensive status, systolic and diastolic blood pressure, creatinine, noradrenaline and adrenaline). In general, continuous covariates were a priori categorized according to quartiles $\left(25^{\circ}, 50^{\circ}\right.$ and $75^{\circ}$ percentiles $)$ of their observed distributions. Given the small number of patients with adrenocortical masses, tumor diameter was categorized 
by tertiles $\left(33.3^{\circ}\right.$ and $66.7^{\circ}$ percentiles). Missing data on creatinine (28 values) were gathered into a specific category. Univariate differences in CgA levels by covariates were assessed by a non-parametric procedure (twotailed median test). The joint effect of disease status and all other covariates on CgA levels were estimated by multiple regression modeling (29). In view of the right-skewed distribution of $\mathrm{CgA}$, data were log-transformed. In the regression analysis, log-transformation of response variable leads to an estimate a statistical index referred to as the median ratio (MR) (30): as a categorical predictor, MR represents the expected median value of $\mathrm{CgA}$ in a category divided by the same index as the reference category. For each MR, $95 \%$ confidence intervals $(95 \%$ CI) were calculated and, to show the explanatory power of each model, the index R2 (coefficient of determination $=$ modelexplained variability/total variability) was computed. Leverage, residual and influence measures were applied to assess the adequacy of the modeling. The statistical significance of each model and each covariate in the model was evaluated by two-tailed F-test. Furthermore, in order to estimate the discriminant power of $\mathrm{CgA}$ and all other continuous covariates on the study group, a non-parametric receiver operating characteristic (ROC) analysis was carried out using disease status as the classification factor (31). In particular, the area under a ROC curve (AUC) was used to estimate the pure accuracy, which represents the probability that a (randomly selected) patient with an adrenocortical mass has a $\mathrm{CgA}$ value higher than a (randomly selected) tumor-free subject. Data were analyzed by Stata statistical software (32).

\section{Results}

Patients with adrenocortical tumors were older, with higher systolic blood pressure values and with greater plasma noradrenaline and creatinine levels than tumor-free subjects (Table 1). Descriptive analysis of the CgA distribution (Table 2 and Fig. 1) showed a statistically significant increase in $\mathrm{CgA}$ levels for patients with adrenocortical tumors as compared with tumorfree subjects. Accordingly, individual data (Fig. 1) indicated that in only one out of 137 tumor-free subjects $(0.7 \%)$ was plasma $\mathrm{CgA}$ above our cut-off for normal $(100 \mathrm{ng} / \mathrm{ml})$. In contrast, the cut-off was exceeded in 20 of 80 patients with adrenocortical tumors (25\%). An increase in plasma $\operatorname{CgA}$ was also found in the older subjects and in those with more elevated plasma creatinine and noradrenaline levels. No significant variation was found for gender, blood pressure or adrenaline levels (Table 2). The joint effect on CgA levels of disease status and other covariates estimated through multiple log-normal regression modeling is shown in Table 3. Using tumor-free subjects as a reference category, a non-linear (parabolic) trend in $\mathrm{CgA}$ median levels was seen as a function of tumor diameter. In particular, the maximum excess $(\mathrm{MR}=1.49,95 \%$ $\mathrm{CI}=1.21-1.84$ ) was found for patients with a lesion diameter ranging from 20 to $30 \mathrm{~mm}$. On average, i.e. irrespective of tumor diameter, patients with an adrenocortical mass showed an estimated 38\% median $\mathrm{CgA}$ excess $(\mathrm{MR}=1.38,95 \% \quad \mathrm{CI}=1.16-1.63) \quad$ in comparison with the same reference (data not shown). A substantial contribution appeared to be made by age at examination (for patients aged over 57 years: $\mathrm{MR}=1.46,95 \% \quad \mathrm{CI}=1.17-1.85)$ and plasma creatinine (for values greater than $1.10 \mathrm{mg} / \mathrm{dl}: \mathrm{MR}=1.52,95 \% \mathrm{CI}=1.19-1.93$ ), while no significant effect of gender, blood pressure or catecholamines was noted.

Table 4 shows pure accuracy values estimated through ROC analysis performed on all continuous covariates. As expected, CgA showed a very good test performance $(\mathrm{AUC}=0.78,95 \% \mathrm{CI}=0.71-0.84)$, though less than that shown by age at examination $(\mathrm{AUC}=0.81,95 \% \mathrm{CI}=0.75-0.87)$ (Fig. 2).

Patients $(n=65)$ who underwent clinical and morphological follow-up, both with normal (75\%) and high (25\%) CgA levels, did not develop signs or symptoms of disease and exhibited no features of malignant transformation of the masses. In the 15 patients with adrenocortical tumors who underwent surgery, plasma $\mathrm{CgA}$ did not change significantly $(80.6 \pm 16.5$ before and $74.3 \pm 16.3 \mathrm{ng} / \mathrm{ml}$ after removal of the mass), a finding observed in both patients with normal $(73 \%)$ and patients with high $(27 \%) \mathrm{CgA}$ values. In particular, in the four cases with elevated $\mathrm{CgA}$, the following were found: patient no. $1=84$ vs basal $107 \mathrm{mg} / \mathrm{dl}$; patient no. $2=212$ vs basal $119 \mathrm{mg} / \mathrm{dl}$; patient no. $3=189$ vs basal $153 \mathrm{mg} / \mathrm{dl}$; patient no. $4=255 \mathrm{vs}$ basal $262 \mathrm{mg} / \mathrm{dl}$.

Immunohistochemical analysis of the removed tumors failed to show $\operatorname{CgA}$ immunoreactivity in any of the specimens examined (Fig. 3). These results were obtained by comparing $\mathrm{CgA}$ expression in medullary thyroid carcinoma (our positive control) with that in the tissues. In no case was distinct cytoplasmatic staining observed and, according to our criteria, all specimens were considered negative.

Since creatinine is a crucial parameter for $\mathrm{CgA}$ values, we compared plasma creatinine in the operated $(0.95 \pm 0.06 \mathrm{mg} / \mathrm{dl})$ and non-operated $(0.97 \pm 0.03$ $\mathrm{mg} / \mathrm{dl})$ patients. No statistical difference was found. Similarly, in the 15 patients with adrenocortical tumors who underwent surgery, plasma creatinine did not change significantly $(0.95 \pm 0.03$ before and $0.98 \pm 0.06 \mathrm{mg} / \mathrm{dl}$ after removal of the mass), a finding observed in both patients with normal and high $\mathrm{CgA}$ values. In particular, in the four cases with elevated $\mathrm{CgA}$, the following values in plasma creatinine were found: patient no. $1=0.7$ vs basal $0.9 \mathrm{mg} / \mathrm{dl}$; patient no. $2=1.2$ vs basal $1.0 \mathrm{mg} / \mathrm{dl}$; patient no. $3=1.1$ vs basal $1.1 \mathrm{mg} / \mathrm{dl}$; patient no. $4=1.2 \mathrm{vs}$ basal $1.1 \mathrm{mg} / \mathrm{dl}$. 
Table 2 Conditional distributions of CgA levels according to factors taken into consideration for analyses.

\begin{tabular}{|c|c|c|c|c|c|c|c|}
\hline Factors and levels & Subjects $(n)$ & Mean & S.D. & Median & Minimum & Maximum & $\boldsymbol{P}$ \\
\hline Disease status & & & & & & & $<0.001$ \\
\hline Tumor-free subjects & 137 & 43.13 & 17.60 & 38.51 & 17.58 & 102.06 & \\
\hline Adrenocortical tumors ${ }^{a}$ & 80 & 83.41 & 67.56 & 62.59 & 23.42 & 392.61 & \\
\hline$<20$ (diameter, $\mathrm{mm}$ ) & 26 & 99.16 & 97.81 & 61.91 & 32.75 & 392.61 & \\
\hline $20-30$ & 29 & 81.71 & 38.98 & 73.67 & 44.64 & 246.62 & \\
\hline$>30$ & 21 & 72.67 & 57.11 & 46.26 & 23.42 & 261.87 & \\
\hline Age at examination (years) & & & & & & & $<0.001$ \\
\hline$\leq 36$ & 52 & 39.14 & 14.95 & 34.80 & 17.58 & 78.69 & \\
\hline $37-49$ & 54 & 54.04 & 47.34 & 44.03 & 21.29 & 353.90 & \\
\hline $50-57$ & 57 & 53.39 & 24.56 & 40.77 & 24.91 & 119.24 & \\
\hline$>57$ & 54 & 84.91 & 70.20 & 60.31 & 26.70 & 392.61 & \\
\hline Gender & & & & & & & 0.958 \\
\hline Male & 136 & 55.31 & 36.98 & 44.16 & 20.35 & 285.96 & \\
\hline Female & 81 & 62.47 & 60.98 & 44.69 & 17.58 & 392.61 & \\
\hline Hypertensive status & & & & & & & 0.336 \\
\hline Normal & 72 & 52.27 & 41.57 & 41.05 & 17.58 & 353.90 & \\
\hline Hypertensive & 145 & 60.81 & 49.89 & 45.65 & 20.35 & 392.61 & \\
\hline Systolic blood pressure $(\mathrm{mmHg})$ & & & & & & & 0.061 \\
\hline$\leq 128$ & 52 & 55.27 & 47.72 & 45.82 & 17.58 & 353.60 & \\
\hline $129-142$ & 57 & 48.96 & 26.13 & 40.29 & 20.35 & 142.02 & \\
\hline $143-154$ & 55 & 56.08 & 39.10 & 40.04 & 21.72 & 261.87 & \\
\hline$>154$ & 53 & 72.32 & 66.74 & 53.03 & 24.77 & 392.61 & \\
\hline Diastolic blood pressure $(\mathrm{mmHg})$ & & & & & & & 0.726 \\
\hline$\leq 80$ & 59 & 54.54 & 45.88 & 40.70 & 17.58 & 353.90 & \\
\hline $81-90$ & 49 & 60.95 & 56.32 & 47.50 & 21.72 & 392.61 & \\
\hline $91-98$ & 56 & 56.69 & 38.78 & 45.16 & 24.77 & 261.87 & \\
\hline$>98$ & 53 & 60.43 & 49.25 & 44.69 & 20.35 & 285.96 & \\
\hline Creatinine (mg/dl) & & & & & & & $<0.001$ \\
\hline$\leq 0.80$ & 37 & 50.26 & 54.86 & 38.51 & 17.58 & 353.90 & \\
\hline $0.81-0.90$ & 72 & 46.74 & 21.78 & 40.01 & 21.29 & 142.02 & \\
\hline $0.91-1.10$ & 37 & 51.85 & 30.96 & 36.95 & 20.35 & 153.30 & \\
\hline$>1: 10$ & 43 & 88.24 & 76.17 & 63.81 & 26.15 & 392.61 & \\
\hline Unknown & 28 & 58.72 & 21.44 & 55.96 & 29.13 & 115.90 & \\
\hline Noradrenaline (pg/ml) & & & & & & & 0.028 \\
\hline$\leq 176.90$ & 55 & 53.08 & 45.87 & 40.29 & 17.58 & 285.96 & \\
\hline $176.91-257.80$ & 54 & 54.38 & 40.17 & 40.26 & 20.35 & 261.87 & \\
\hline $257.81-351.50$ & 54 & 53.19 & 29.03 & 45.96 & 21.79 & 162.05 & \\
\hline$>351.50$ & 54 & 71.36 & 65.59 & 56.07 & 21.29 & 392.61 & \\
\hline Adrenaline (pg/ml) & & & & & & & 0.241 \\
\hline$\leq 16.7$ & 54 & 48.85 & 22.81 & 43.39 & 23.42 & 142.02 & \\
\hline $16.8-31.2$ & 55 & 48.95 & 25.86 & 37.64 & 17.58 & 119.24 & \\
\hline $31.3-44.8$ & 54 & 67.81 & 61.56 & 47.03 & 20.35 & 353.90 & \\
\hline$>44.8$ & 54 & 66.47 & 61.76 & 49.09 & 17.99 & 392.61 & \\
\hline Whole sample & 217 & 57.98 & 47.37 & 44.69 & 17.58 & 392.61 & \\
\hline
\end{tabular}

$P$, significance level of the non-parametric median test.

a Missing tumor size value in four cases.

\section{Discussion}

Since neuroendocrine cells synthesize and secrete $\mathrm{CgA}$, this protein is generally utilized as a tissue and serum marker of chromaffin system tumors (4-14). However, some epithelial tumors may also acquire the ability to produce $\mathrm{CgA}$ (15-18), a neuroendocrine transformation associated with poor prognosis (19-21).

The aim of our study was to evaluate whether adenomas arising from the adrenal cortex, a tissue of epithelial origin, are associated with high $\mathrm{CgA}$ levels and whether such tumors may express and release this protein. For this reason, plasma CgA levels were investigated in a large selected cohort of patients with benign, non-functioning adrenocortical tumors after careful exclusion of tumors of medulla origin. While the majority of the patients were followed-up, 15 were operated on and the specimens used for immunohistochemical investigations.

Our results showed that the presence/absence of the adrenal mass, age and plasma creatinine affect $\mathrm{CgA}$ status, with a clear positive correlation between $\operatorname{CgA}$ levels and these parameters. Log-CgA multiple regression on all available covariates confirmed that patients with adrenal masses have up to $49 \%$ greater median $\mathrm{CgA}$ values than tumor-free patients, and that the relation between mass and $\mathrm{CgA}$ values was positive and statistically significant. Accordingly, ROC analysis indicated that the probabilities of finding high $\mathrm{CgA}$ levels are $78 \%$ greater in the presence than in the 

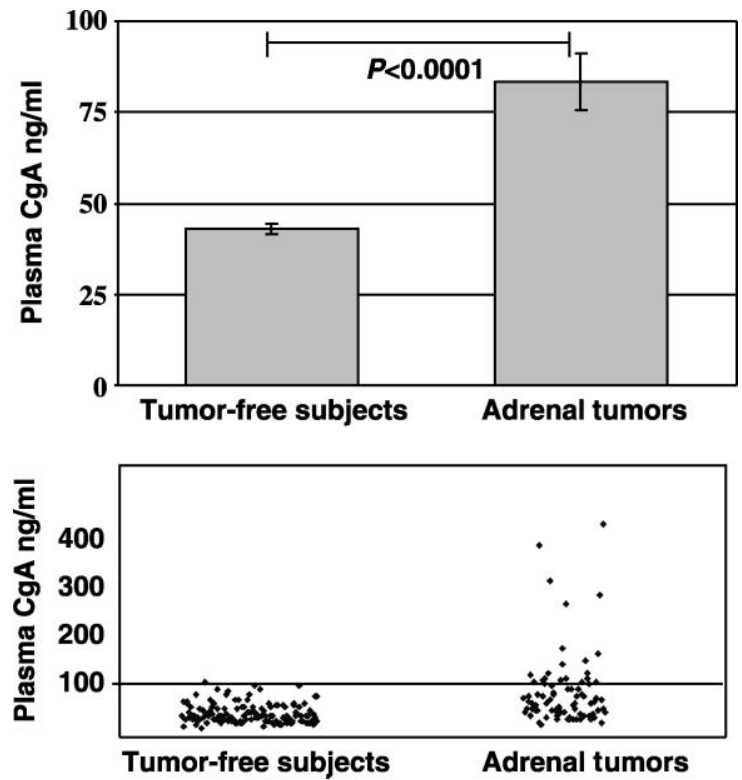

Figure 1 Means $\pm S$.E. of plasma $\mathrm{CgA}$ in tumor-free subjects and in patients with adrenocortical tumors. The statistical significance is shown (upper graph). Individual data of $\mathrm{CgA}$ values in both groups are given. The solid line represents the upper limit of normal values (lower graph).

absence of the adrenal mass, so that $\mathrm{CgA}$ appears to be a strong discriminant for the presence/absence of a mass. However, given the small number of significant predictors and the modest value of $R^{2}(0.38)$, it is possible that the estimated difference and non-linear trend in $\mathrm{CgA}$ levels in relation to the subjects' disease status and stage might be biased by the lack of other predictors not considered in the present analysis.

The biological significance of this strong association is, at present, unclear. It is possible that $\operatorname{CgA}$ was produced and released in large amounts by some adrenocortical adenomas, as occurs for other tumors of epithelial origin (15-18). This could imply neuroendocrine transformation of the tumor and thus be considered a marker of malignancy. However, such a hypothesis is unlikely for a number of reasons. In patients who underwent surgery, both with high and normal $\mathrm{CgA}$ values, removal of the mass was not associated with significant modifications of this protein. Furthermore, adrenal adenomas of these patients never expressed CgA immunoreactivity, even in patients with high CgA levels. Finally, at present no patient has shown morphological modifications of the adrenal masses or has developed signs or symptoms of diseases. Taken together, these data indicated that the elevated CgA levels in patients with adrenal masses are not due to the presence of the tumor and cannot therefore be considered as markers of tumoral neuroendocrine transformation.

Another possibility is that $\mathrm{CgA}$ was primarily elevated, causing and/or contributing to development and/or growth of at least some adrenal tumors. This hypothesis
Table 3 Joint effect on CgA levels on disease status and other covariates estimated through multiple log-normal regression modeling.

\begin{tabular}{|c|c|c|c|c|}
\hline Factors and levels & MR & $95 \% \mathrm{CL}$ & F-test & $P$ value \\
\hline Constant & 29.71 & $23.07-38.29$ & - & - \\
\hline Disease status & & & 6.56 & $<0.001$ \\
\hline $\begin{array}{l}\text { Tumor-free subjects } \\
\text { Adrenocortical tumors }\end{array}$ & 1.00 & Ref. & & \\
\hline$<20 \mathrm{~mm}$ & 1.45 & $1.16-1.80$ & & \\
\hline $20-30 \mathrm{~mm}$ & 1.49 & $1.21-1.84$ & & \\
\hline$>30 \mathrm{~mm}$ & 1.12 & $0.87-1.44$ & & \\
\hline Gender & & & 0.10 & 0.758 \\
\hline Male & 1.00 & Ref. & & \\
\hline Female & 1.03 & $0.88-1.20$ & & \\
\hline Age at examination (years) & & & 4.22 & 0.007 \\
\hline$\leq 36$ & 1.00 & Ref. & & \\
\hline $37-49$ & 1.10 & $0.91-1.32$ & & \\
\hline $50-57$ & 1.18 & $0.98-1.42$ & & \\
\hline$>57$ & 1.46 & $1.17-1.85$ & & \\
\hline Hypertensive status & & & 0.48 & 0.489 \\
\hline Normal & 1.00 & Ref. & & \\
\hline Hypertensive & 0.95 & $0.82-1.10$ & & \\
\hline Creatinine (mg/dl) & & & 4.02 & 0.004 \\
\hline$\leq 0.80$ & 1.00 & Ref. & & \\
\hline $0.80-0.90$ & 1.10 & $0.90-1.35$ & & \\
\hline $0.91-1.10$ & 1.13 & $0.89-1.44$ & & \\
\hline$>1.10$ & 1.52 & $1.19-1.93$ & & \\
\hline Unknown & 1.23 & $0.96-1.56$ & & \\
\hline Noradrenaline (pg/ml) & & & 0.46 & 0.708 \\
\hline$\leq 176.90$ & 1.00 & Ref. & & \\
\hline $176.91-257.80$ & 1.05 & $0.89-1.25$ & & \\
\hline $257.81-351.50$ & 1.10 & $0.92-1.31$ & & \\
\hline$>351.50$ & 1.09 & $0.91-1.30$ & & \\
\hline Adrenaline (pg/ml) & & & 1.87 & 0.136 \\
\hline$\leq 16.7$ & 1.00 & Ref. & & \\
\hline $16.8-31.2$ & 0.92 & $0.77-1.10$ & & \\
\hline $31.3-44.8$ & 1.09 & $0.92-1.30$ & & \\
\hline$>44.8$ & 1.12 & $0.93-1.35$ & & \\
\hline
\end{tabular}

Overall F-test $=6.66 ; P$ value $<0.001 ; R^{2}=0.38$

$95 \% \mathrm{CL}=95 \%$ confidence limits; $P$ value $=$ significance value of the F-test; Constant $=$ estimated baseline median value; Ref. $=$ reference category; MR, median ratio.

derives from the fact that the $\mathrm{CgA}$ molecule usually behaves as a prohormone, generating various biologically active peptides (33) able to influence growth, morphogenesis and progression of endocrine tumors (34-40). Unfortunately, our study was not planned to verify this aspect which, however, deserves further investigation.

Table 4 Results of non-parametric ROC analysis performed on each continuous covariate.

\begin{tabular}{lcc}
\hline Variables & AUC & 95\% CL \\
\hline Age at examination (years) & 0.81 & $0.75-0.87$ \\
Chromogranine $(\mathrm{ng} / \mathrm{ml})$ & 0.78 & $0.71-0.84$ \\
Noradrenaline $(\mathrm{pg} / \mathrm{ml})$ & 0.65 & $0.56-0.74$ \\
Systolic blood pressure $(\mathrm{mmHg})$ & 0.63 & $0.54-0.71$ \\
Adrenaline $(\mathrm{pg} / \mathrm{ml})$ & 0.58 & $0.50-0.67$ \\
Creatinine $(\mathrm{mg} / \mathrm{dl})$ & 0.58 & $0.49-0.67$ \\
Diastolic blood pressure $(\mathrm{mmHg})$ & 0.47 & $0.39-0.56$ \\
\hline
\end{tabular}

AUC, area under the curve; CL, confidence limit. 


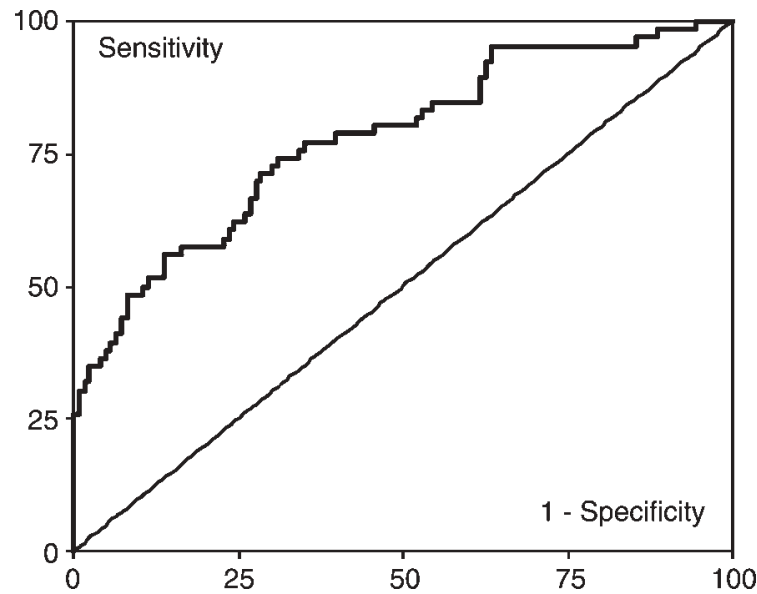

Figure 2 Non-parametric ROC curve applied to $\mathrm{CgA}$. AUC $=0.78$ and $95 \% \mathrm{Cl}=0.71-0.84$ estimate the pure accuracy which is the diagnostic performance of the study biomarker.
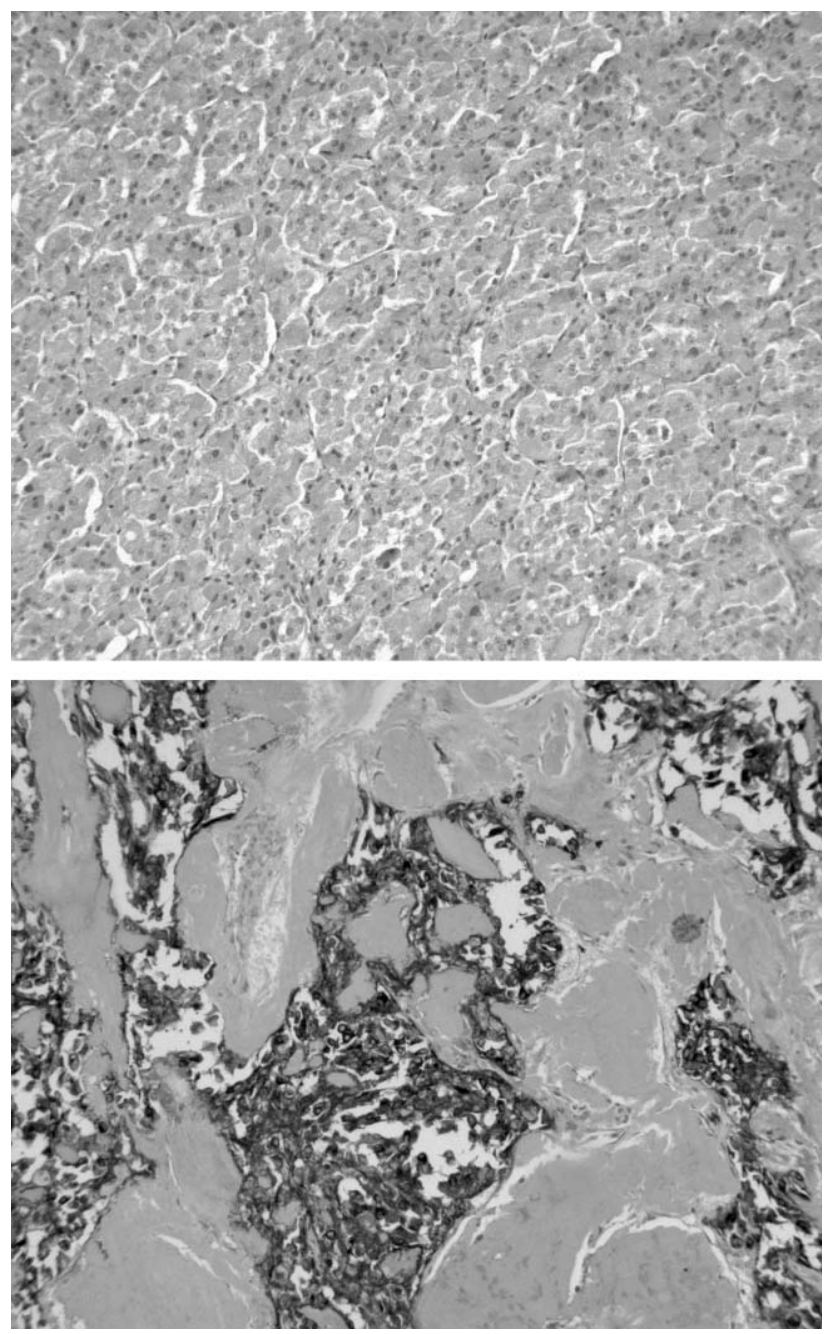

Figure 3 Total absence of immunostaining in adenoma tissue of one of the patients (upper) in comparison with clearly detectable $\mathrm{CgA}$ immunoreactivity in medullary thyroid carcinoma (lower). Magnification $\times 10$.
Nevertheless, even though we cannot offer a clear explanation for the strong association between high CgA levels and the presence of adrenocortical adenomas, our work may constitute a basis for further investigations in this field. In addition, it may also be clinically useful by indicating that, in patients with an adrenocortical mass, elevated $\operatorname{CgA}$ values do not represent a marker of potential malignant transformation of the lesion.

In conclusion, our data show a strong association between benign adrenocortical tumors and elevated $\mathrm{CgA}$ levels, a finding not entirely explicable by the older age and higher creatinine levels of patients with an adrenal mass. CgA hypersecretion is not due to adenoma tissue, which never shows immunoreactivity for $\mathrm{CgA}$. Finally, elevated $\mathrm{CgA}$ is not a marker of neuroendocrine transformation of cortical adenomas and therefore of a possible shift toward malignancy.

\section{Acknowledgements}

We are grateful to Mrs P Tabucchi and Mr R Birindelli for their precious technical assistance.

\section{References}

1 Konecki DS, Benedum UM, Gerdes HH \& Huttner WB. The primary structure of human chromogranin A and pancreastatin. Journal of Biological Chemistry 1987262 17026-17030.

2 Simon JP \& Aunis D. Biochemistry of the chromogranin A protein family. Biochemical Journal 1989262 1-13.

3 Cetin Y \& Grube D. Topology of chromogranins in secretory granules of endocrine cells. Histochemistry $199196301-310$.

4 Deftos LJ, Linnoila RI, Carney DN, Burton DW, Leong SS, O'Connor DT, Murray SS \& Gazdar AF. Demonstration of chromogranin A in human neuroendocrine cell lines by immunohistology and immunoassay. Cancer 198862 92-97.

5 Weiler R, Feichtinger H, Schmid KW, Fischer-Colbrie R, Grimelius L, Cedermark B, Papotti M, Bussolati G \& Winkler H. Chromogranin A and B and secretogranin II in bronchial and intestinal carcinoids. Virchows Archiv A - Pathological Anatomy and Histopathology $1987 \mathbf{4 1 2} 103-109$.

6 Totsch M, Muller LC, Hittmair A, Ofner D, Gibbs AR \& Schmid KW. Immunohistochemical demonstration of chromogranins A and B in neuroendocrine tumors of the lung. Human Pathology 199223 312-316.

7 Rosa P \& Gerdes HH. The granin protein family: markers for neuroendocrine cells and tools for the diagnosis of neuroendocrine tumors. Journal of Endocrinological Investigation 199417 207-225.

8 Deftos LJ. Chromogranin A: its role in endocrine function and as an endocrine and neuroendocrine tumor marker. Endocrine Reviews $199112181-187$.

9 Stridsberg M \& Husebye ES. Chromogranin A and chromogranin $\mathrm{B}$ are sensitive circulating markers for phaeochromocytoma. European Journal of Endocrinology 1997136 67-73.

10 Baudin E, Gigliotti A, Ducreux M, Ropers J, Comoy E, Sabourin JC, Ridart JM, Cailleux AF, Bonacci A, Ruffie P \& Schlumberge M. Neuron-specific enolase and chromogranin A as markers of neuroendocrine tumours. British Journal of Cancer $1998 \mathbf{7 8}$ 1102-1107.

11 Rao F, Keiser HR \& O'Connor DT. Malignant pheochromocytoma. Chromaffin granule transmitters and response to treatment. Hypertension 200036 1045-1052. 
12 Bernini GP, Moretti A, Ferdeghini M, Ricci S, Letizia C, D’Erasmo E, Argenio GF \& Salvetti A. A new human chromogranin 'A' immunoradiometric assay for the diagnosis of neuroendocrine tumours. British Journal of Cancer $2001 \mathbf{8 4} 636-642$.

13 Seregni E, Ferrari L, Bajetta E, Martinetti A \& Bombardieri E. Clinical significance of blood chromogranin A measurement in neuroendocrine tumours. Annals of Oncology 200112 S69-S72.

14 Baudin E, Bidart JM, Bachelot A, Ducreux M, Elias D, Ruffie P \& Schlumberger M. Impact of chromogranin A measurement in the work-up of neuroendocrine tumors. Annals of Oncology 200112 S79-S82.

15 di Sant'Agnese PA \& Cockett AT. Neuroendocrine differentiation in prostatic malignancy. Cancer 199678 357-361.

16 Rumpold H, Heinrich E, Untergasser G, Hermann M, Pfister G, Plas E \& Berger P. Neuroendocrine differentiation of human prostatic primary epithelial cells in vitro. Prostate 200253 101-108.

17 Kadmon D, Thompson TC, Lynch GR \& Scardino PT. Elevated plasma chromogranin-A concentrations in prostatic carcinoma. Journal of Urology 1991146 358-361.

18 Leone N, Pellicano R, Brunello F, Rizzetto M \& Ponzetto A. Elevated serum chromogranin A in patients with hepatocellular carcinoma. Clinical and Experimental Medicine 20022 119-123.

19 Bosman FT. Neuroendocrine cells in non-endocrine tumors: what does it mean? Verhandlungen Deutschen Gesellschaft Fur Pathology $19978162-72$.

20 di Sant'Agnese PA \& de Mesy Jensen KL. Neuroendocrine differentiation in prostatic carcinoma. Human Pathology $1987 \mathbf{1 8}$ 849-856.

21 Theodorescu D, Broder SR, Boyd JC, Mills SE \& Frierson HF Jr. Cathepsin D and chromogranin A as predictors of long term disease specific survival after radical prostatectomy for localized carcinoma of the prostate. Cancer $1997802109-2119$.

22 Grumbach MM, Biller BM, Braunstein GD, Campbell KK, Carney JA, Godley PA. Harris EL, Lee JK, Oertal YC, Posner MC Schlechte JA \& Wiegand HS. Management of the clinically inapparent adrenal mass ("incidentaloma"). Annals of Internal Medicine 2003138 424-429.

23 Bernini G, Moretti A \& Salvetti A. Chromogranin 'A' in normal subjects, essential hypertensives and adrenalectomized patients. Clinical Endocrinology 200257 41-50.

24 Hsiao RJ, Mezger MS \& O'Connor DT. Chromogranin A in uremia: progressive retention of immunoreactive fragments. Kidney International 199037 955-964.

25 Sanduleanu S, Stridsberg M, Jonkers D, Hameeteman W, Biemond I, Lundqvist G, Lamers C \& Stockbrugger RW. Serum gastrin and chromogranin A during medium- and long-term acid suppressive therapy: a case-control study. Alimentary Pharmacology and Therapeutics 199913 145-153.

26 Chalmers J, MacMahon S, Mancia G, Whitworth J, Beilin L, Hansson L, Neal B, Rodgers A, Ni Mhurchu C \& Clark T. World Health Organization - International Society of Hypertension Guidelines for the management of hypertension. Guidelines sub-committee of the World Health Organization. Clinical and Experimental Hypertension 199921 1009-1060.

27 Krstulovic AM, Dziedzic SW, Bertani-Dziedzic L \& DiRico DE. Plasma catecholamines in hypertension and pheochromocytoma determined using ion-pair reversed-phase chromatography with amperometric detection: investigation of the separation mechanism and clinical methodology. Journal of Chromatography 1981 $217523-537$.

28 Degorce F, Goumon Y, Jacquemart L, Vidaud C, Bellanger L, Pons-Anicet D, Seguin P, Metz-Boutigue MH \& Aunis D. A new human chromogranin A ( $\mathrm{CgA})$ immunoradiometric assay involving monoclonal antibodies raised against the unprocessed central domain (145-245). British Journal of Cancer $1999 \mathbf{7 9}$ $65-71$.

29 Kleinbaum DG, Kupper W, Muller KE \& Nizam A. In Applied Regression Analysis and Other Multivariable Methods, ch 8, pp 102-123. Pacific Grove: Duxbury Press, 1998.

30 Miettinen OS. Theoretical Epidemiology. New York: Wiley and Sons, 1985.

31 Hanley JA \& McNeil BJ. The meaning and use of the area under a receiver operating characteristic (ROC) curve. Radiology 1982 $14329-36$.

32 Stata Corp, Stata Statistical Software: release 7.0., College Station, TX, USA: Stata Corporation, 2001.

33 Trifaro JM. Molecular biology of the chromaffin cell. Annals of the New York Academy of Science 2002971 11-18.

34 Aardal S \& Helle KB. The vasoinhibitory activity of bovine chromogranin A fragment (vasostatin) and its independence of extracellular calcium in isolated segments of human blood vessels. Regulatory Peptides 199241 9-18.

35 Aardal S, Helle KB, Elsayed S, Reed RK \& Serck-Hanssen G. Vasostatins, comprising the N-terminal domain of chromogranin A, suppress tension in isolated human blood vessel segments. Journal of Neuroendocrinology 19935 405-412.

36 Helle KB. Vasostatins. Vascular targets. Advances in Experimental Medicine Biology $2000 \mathbf{4 8 2} 225-238$.

37 Lugardon K, Chasserot-Golaz S, Kieffer AE, Maget-Dana R, Nullans G, Kieffer B, Aunis D \& Metz-Boutigue MH. Structural and biological characterization of chromofungin, the antifungal chromogranin A-(47-66)-derived peptide. Journal of Biological Chemistry 2001276 35875-35882.

38 Colombo B, Curnis F, Foglieni C, Monno A, Arrigoni G \& Corti A. Chromogranin A expression in neoplastic cells affects tumor growth and morphogenesis in mouse models. Cancer Research $200262941-946$.

39 Gasparri A, Sidoli A, Sanchez LP, Longhi R, Siccardi AG, Marchisio PC \& Corti A. Chromogranin A fragments modulate cell adhesion. Identification and characterization of a proadhesive domain. Journal of Biological Chemistry $1997 \mathbf{2 7 2}$ 20835-20843

40 Soriano JV, Pepper MS, Taupenot L, Bader MF, Orci L \& Montesano R. Chromogranin A alters ductal morphogenesis and increases deposition of basement membrane components by mammary epithelial cells in vitro. Biochemical and Biophysical Research Communications 1999259 563-568.

Received 3 March 2004

Accepted 5 May 2004 